\title{
A multiplicidade da classe trabalhadora na práxis marxiana e sua atualidade
}

Maria Clara Lima de Menezes*

DOI: 10.11606/issn.2318-8855.v10i1p590-599

MATTOS, Marcelo Badaró. A classe trabalhadora: de Marx ao nosso tempo. São Paulo: Boitempo, 2019.

* Graduanda do bacharelado em Ciências Sociais na Universidade Federal da Paraíba (UFPB), pesquisadora no Laboratório de Estudos e Pesquisas em Políticas Públicas e Trabalho (LAEPT), - Gostaria de agradecer imensamente o belo e importante trabalho dos pareceristas, bem como a atenção dada não só ao texto, mas ao trabalho tanto do autor do livro como de quem o resenha. 


\section{resenhas}

\section{A multiplicidade da classe trabalhadora na práxis marxiana e sua atualidade}

Ao passo que o capitalismo é cíclico e dinâmico, a classe trabalhadora em si é múltipla e, por sua vez, também dinâmica. Acompanha não só os ciclos do capital, mas também as mudanças históricas e sociais que marcam os cenários político e econômico de seu tempo. No entanto, não nos cabe dizer que o teor máximo da classe trabalhadora, a exploração sofrida, assim como sua capacidade emancipatória e revolucionária, se perdem (ou devem se perder) nesse processo. Apesar das mudanças políticas e dos ciclos do capitalismo, as características acima mencionadas acompanham esta classe em toda a sua trajetória. É nesse sentindo que a teoria e a prática marxiana ${ }^{1}$ se mantêm ao longo do tempo. Não se deve considerá-la plenamente determinista econômica e exclusivamente teórica, mas múltipla, amparada na vivência ativa e com um projeto de classe que considera as especificidades da classe trabalhadora e o papel das lutas de classes enquanto fator construtivo da sociedade e do indivíduo ao longo da história.

O livro aqui resenhado toma como base a discussão acerca do papel revolucionário da classe trabalhadora na teoria-prática de Marx e Engels, para estipular um questionamento central: Como é e como se configura a classe trabalhadora hoje? Essa questão é primordial para pensar não só a obra, mas a própria teoria marxiana e a organização da nossa sociedade. Esse debate está nas primeiras páginas do livro A classe trabalhadora: de Marx a nosso tempo, do historiador do trabalho Marcelo Badaró Mattos², publicado em junho de 2019. Além de “dar cara

\footnotetext{
${ }^{1}$ Quando falamos em "teoria marxiana", faz-se referência à obra e a teoria direta e original de Karl Marx, muitas vezes em conjunto com Friedrich Engels. Ao contrário da "teoria marxista", advinda dos estudiosos e seguidores dos autores, estes com uma interpretação própria.

${ }^{2}$ Marcelo Badaró Mattos possui graduação em História (Universidade Federal do Rio de Janeiro - UFRJ) e Mestrado e Doutorado em História Social (Universidade Federal Fluminense - UFF). É especialista em História do Brasil República e História Social do Trabalho, tendo publicado trabalhos principalmente nesta última área, com união entre urbanidades, as relações de trabalho e os marxismos. Informações disponíveis no currículo do autor em: < http://lattes.cnpq.br/8081498917287880>. Acesso em 10 de
} 


\section{resenhas}

\section{Maria Clara Lima de Menezes}

e corpo" à teoria marxiana enquanto prática, tendo a classe trabalhadora como elemento central, o livro se insere num cenário político e econômico onde os escritos de Marx e Engels tornam-se ainda mais atuais.

Esquematicamente, o livro divide-se em quatro partes, a fim de colocar em pauta os escritos de Marx, dos marxistas, historiadores sociais etc., e o entendimento da classe trabalhadora nessa variedade de áreas do pensamento. A primeira parte do livro está dividida a partir de relações estabelecidas pelas conceituações de classe, assim como o vocabulário empreendido por elas. Nessa primeira parte, o autor opta por um recorte didático entre as dimensões objetivas e subjetivas do conceito de classe trabalhadora, que perpassa vários momentos da produção de Marx e Engels. Tais dimensões não são vistas como elementos separados, mas atuam conjuntamente na realidade das classes sociais, especialmente da classe trabalhadora. O que o autor pretende é trazer a justaposição desses aspectos e perceber as características das classes acima de suas diferenças.

A segunda e quarta seções perfazem o debate entre a conceituação de Marx e dos marxismos acerca do proletariado, vistos na primeira parte, em relação com elementos empíricos, dados estatísticos e análises sobre a realidade das trabalhadoras e dos trabalhadores de hoje. A terceira parte centra-se na análise de algumas teorias de autores do hemisfério Norte sobre a caracterização dos profissionais livres, que se difundiram nas últimas décadas. Estas relativizam e até negam um aspecto central da análise de Marx sobre o proletariado: o seu potencial enquanto sujeito histórico e, por conseguinte, capaz de uma transformação emancipadora. O autor também analisa o debate presente nas Ciências Sociais e na historiografia sobre a mesma classe, criando uma interdisciplinaridade na análise e

nov. de 2020. 


\section{resenhas}

\section{A multiplicidade da classe trabalhadora na práxis marxiana e sua atualidade}

visão sobre a teoria marxiana e o potencial da classe trabalhadora de hoje, questionada por alguns autores.

A bandeira política levantada por Karl Marx (1818-1883) e Friedrich Engels (1820-1895) vai muito além da visão puramente econômica sobre a dicotomia entre os proletários e os detentores dos meios de produção, a burguesia. A discussão sobre classes sociais está presente nos trabalhos de Marx, especialmente quando analisamos a sua dita "trilogia política", que se inicia com As lutas de classes na França: de 1848 a 1950 (2012), originalmente publicada em 1850, continua com 018 brumário de Luís Bonaparte (2011), de 1852, e se conclui com A guerra civil na França (2011), de 1871, seguindo para seus trabalhos posteriores, tanto solo quanto em conjunto com Engels.

Assim, Marx e Engels se encontram no momento da formação da classe trabalhadora, mas não a inventaram enquanto uma categoria de análise. Como pontua Badaró, esse entendimento já se verificava tanto no vocabulário da época, quanto na consciência daquele grupo com o qual eles se identificariam politicamente. O que fizeram foi elaborar um método de análise junto com um conjunto de investigações que fizeram da categoria "classes sociais" seu principal alicerce. Como coloca Michael Löwy, o que Marx e Engels fizeram emergir foi “[...] a síntese dialética, a superação dos elementos fragmentários, esparsos, parciais, das diversas experiências e ideologias do movimento operário e a produção de uma teoria coerente, racional e adequada à situação do proletariado" (LÖWY, 2002, p. 138 apud MATTOS, 2019, p. 21). Entretanto, considera-se que essa síntese dialética, como mencionado por Löwy, traz consigo espaços em branco a serem preenchidos e atualizados por suas diversas frentes de análise (de raça/cor/etnia, gêneros, geografia etc.). 


\section{resenhas}

\section{Maria Clara Lima de Menezes}

Consideramos que Marx não chegou a aprofundar de fato a dimensão de como essa estrutura de classes e exploração do proletariado impactava as diversas camadas da classe trabalhadora, especialmente o lugar ocupado pelas mulheres na estrutura produtiva e seu papel reprodutivo. Porém, como veremos a partir do trabalho de Mattos aqui resenhado, Marx não estava alheio às diversas dimensões de exploração que marcava a sociedade capitalista em execução em seu tempo, longe de uma interpretação puramente economicista.

Como Mattos pontua, Marx e Engels não mergulharam na pauta da luta de classes em curso baseando-se apenas em uma teoria. À luz dos conflitos da época, da experiência burguesa que marcou com maior espaço a vida de Engels, e também do início da mobilização da classe trabalhadora que os autores presenciaram em sua estada na Inglaterra, eles viram ali um solo propício não só para a teoria revolucionária, mas para o próprio estabelecimento do proletariado como elemento central desses conflitos. Marx e Engels escreveram, portanto, em um tempo de efervescência dos movimentos sociais e trabalhistas e de ascensão da união sindical, em contrapartida ao aceleramento da exploração pela sociedade industrial que tomava corpo ali, a seus olhos, num pós Revolução Francesa (1789-1799) e no curso do aprimoramento da Revolução Industrial (1790-1840).

Nesse momento, a Inglaterra se constituiu como um locus privilegiado para entender a formação do proletariado aos moldes industriais, uma classe explorada pela burguesia e pela necessidade de alimentar a produção de capital. Entretanto, falar de classe, organizada e orientada politicamente, apenas nos moldes europeus ou, especificamente, inglês, é entender o proletariado ou a classe trabalhadora como resguardado a apenas um momento histórico, imóvel no tempo, não passível de mudanças no que concerne a suas demandas, às diferenças entre trabalhadores etc. 


\section{resenhas}

\section{A multiplicidade da classe trabalhadora na práxis marxiana e sua atualidade}

O modelo europeu e a dimensão dos proletários assalariados, apenas, não exprimem toda a trajetória da classe trabalhadora. Esse modelo é a exceção, e não a regra, para entender a luta pelos meios de produção e a própria emancipação política e humana do proletariado.

Por esse motivo, agora, com todos os elementos da produção postos na modernidade, a crítica elaborada por Marx não se refere apenas ao capitalismo de forma geral e às formas de produção e reprodução do capital. Mais adiante, volta-se para a concepção idílica, como ele coloca, da Economia Política quanto ao tempo primitivo da geração do capital $^{3}$. Marx não só critica essa dimensão idílica (e conservadora) da Economia Política, comparando-a à concepção teológica do “pecado original", como também critica a ingenuidade de se pensar por esses termos, sem considerar a violência, a subjugação e o assassínio desempenhado pelas grandes potências para expropriar e roubar as colônias e seus povos autóctones como forma de enriquecimento do Centro.

Com isso, o capital não só supõe a separação entre os trabalhadores e os meios de produção, mas passa a reproduzir essa separação em escala cada vez maior. Desse fato decorre não só a dificuldade dos trabalhadores de terem consciência da sua inserção nesse jogo, mas também a lógica capitalista (geográfica): entre o Centro (Norte global) e Periferia (Sul global); entre os donos dos meios de produção - a tecnologia necessária - e os vendedores de sua força de trabalho - a matéria-prima. Assim, reproduz as desigualdades e separações tanto no espaço físico

\footnotetext{
${ }^{3}$ Essa concepção acreditava que, no início de tudo, havia dois grupos: de um lado, os que agiam de forma parcimoniosa e resguardavam seus bens; de outro, os que gastavam seus bens "como se não houvesse amanhã", gerando, com isso, os que possuíam os meios de produzir e os que nada mais possuíam, a não ser sua própria "carne e sangue", na forma da força de trabalho.
} 


\section{resenhas}

Maria Clara Lima de Menezes

quanto no espaço social ${ }^{4}$ (BOURDIEU, 2008), caracterizando a agência de classe e a própria classe trabalhadora, que é entrecortada e subjugada pelas diferentes lógicas de opressão: de gênero, sexualidade, raça/etnia/cor etc.

Essa relação, então, entre Centro e Periferia e os diferentes perfis de trabalhadores, é resgatada por Mattos para responder à pergunta elencada por ele no início do livro, no que concerne ao conteúdo múltiplo dessa classe e de como ela se coloca na atualidade. É válido mencionar que, especialmente nos últimos anos da história do Brasil, durante governos petistas $(2002-2016)^{5}$, a relação de classe foi relegada a um patamar alfanumérico, quando analisada a separação por classes “A, B, C, D, E" a partir da sua faixa de renda, em uma estratificação de grupos sociais considerando sua capacidade de consumo. Essa análise alfanumérica das classes deixa de lado expressões como "classe trabalhadora", "classe operária" ou "proletariado", o que tende a esvaziar o conteúdo político de classe.

Nessa mentalidade de distinção entre as classes, considerando sua faixa de consumo, a "lógica da ação coletiva", analisada por Mancur Olson (2015) e a capacidade de elaboração política desses grupos sociais, é diminuída. As classes,

\footnotetext{
${ }^{4}$ Pierre Bourdieu, sociólogo francês e crítico do marxismo, elabora uma concepção de espaço físico e espaço social, utilizando-se de seus conceitos de habitus, campo e capital. Os espaços físicos e sociais são relacionais e operam numa lógica de realização mútua: quanto ao espaço físico, que é o local onde o indivíduo está situado, seu lugar é ocupado no mundo a partir da dimensão social e dos processos de hierarquização; quanto ao espaço social, que expõe a distância que esse agente está em relação ao outro e em relação a si mesmo, é ocupado a partir de um (ou de todos) os capitais (cultural, econômico, simbólico e social) obtidos, que o posicionam tanto num contexto de embates dentro de um mesmo campo, quanto entre diferentes campos.

${ }^{5}$ Dadas as políticas públicas e sociais de acesso ao crédito e a uma, mesmo que mínima, redistribuição de renda, as camadas mais pobres do país começaram a galgar acesso a lugares e posições historicamente ocupados pelas classes médias, em grande medida, e as elites, tais como as universidades, a possibilidade de compra de moradias, a frequência em centros de compras (shoppings) e afins. Essas mudanças se devem, principalmente, à ampliação do programa Bolsa Família e à criação do programa de subsídio habitacional "Minha casa, minha vida" (MCMV), ambos durante os governos Lula (2002-2010).
} 


\section{resenhas}

\section{A multiplicidade da classe trabalhadora na práxis marxiana e sua atualidade}

tanto de uma perspectiva relacional de Max Weber (1999) quanto da do materialismo histórico empreendido por Marx e Engels, exprime uma face que é fluida, não estática, considerando a sua capacidade emancipatória, alocando a classe trabalhadora e seus participantes em uma condição de sujeitos próprios de sua dinâmica política.

No que se refere à capacidade emancipatória e revolucionária da classe trabalhadora, ela não se dá de maneira espontânea, determinada historicamente enquanto fenômeno datado e isolado. Como coloca o autor a partir da teoria de Marx, o que caracteriza a humanidade é sua intencionalidade: o que fazemos intencionalmente para produzir nossa sobrevivência, ao mesmo tempo em que modificamos a natureza. E isso só é possível a partir do processo de trabalho e das mudanças sociais.

No entanto, nesse circuito, pode conter uma contra tendência: a possibilidade da mobilização e revolução dos trabalhadores, gerando uma emancipação. Nesse sentido, o objetivo principal do livro de Mattos é privilegiar a perspectiva que busca identificar as classes de acordo com as relações estabelecidas por homens e mulheres, com suas diferentes dinâmicas de sexo/gênero, para produzir e reproduzirse socialmente, a fim de perceber fatores como a consciência coletiva e a ação política das classes. “Dessa forma, podem-se perceber as classes, e os conflitos que se estabelecem entre elas, como processos e relações historicamente situados, decisivos para compreensão da dinâmica mais ampla da transformação social" (MATTOS, 2019, p. 10).

Busca, também, representar uma relação entre trabalhos publicados anteriormente pelo autor, revisitados, que servem como ponto de partida para 


\section{resenhas}

\section{Maria Clara Lima de Menezes}

elaboração de uma introdução e síntese nessa incursão sobre o conceito de classe marxiano e como ele sofreu alterações pelas diferentes perspectivas (idealistas e materialistas) que se apropriaram dele. Pensar a teoria-prática de Marx e Engels na atualidade, tendo como pano de fundo as mudanças nas dimensões política e econômica, é ter num cenário mais amplo, a partir de um esforço em unir teoria e a prática, o pensamento de uma intervenção transformadora da classe trabalhadora nas atuais relações sociais.

O autor pretende, assim, trabalhar as múltiplas dimensões da luta pela emancipação, que é a marca da obra marxiana e engeliana. Volta-se para as diversas dimensões da emancipação (gênero, raça/cor/etnia etc.), como também dos conflitos anticoloniais trazidos pelas obras de Marx e das diversas formas assumidas pela classe trabalhadora dentro do sistema capitalista. Estes se colocam como pressupostos necessários para se entender como se dá a luta de classes e a própria estruturação da classe trabalhadora. Como coloca Mattos ao longo do livro, principalmente ao analisar as diferentes visões sobre o proletariado, o trabalho ainda é elemento central da sociedade e a classe trabalhadora (em suas debilidades e potências) está mais viva e existente que nunca.

\section{Referências}

BOURDIEU, Pierre (coord.). A miséria do mundo. Rio de Janeiro: Vozes, 2008.

ENGELS, Friedrich. A situação da classe trabalhadora na Inglaterra. São Paulo: Boitempo, 2008.

LÖWY, Michael. A teoria da revolução no jovem Marx. Petrópolis: Vozes, 2002.

MARX, Karl. O Capital, vol. 1. São Paulo: Boitempo, 2011.

Os despossuídos: debates sobre a lei referente ao furto de madeira. São

Paulo: Boitempo, 2017. 


\section{resenhas}

A multiplicidade da classe trabalhadora na práxis marxiana e sua atualidade . As lutas de classes na França de 1848 a 1850. São Paulo: Boitempo, 2012.

O 18 brumário de Luís Bonaparte. São Paulo: Boitempo, 2011.

A guerra civil na França. São Paulo: Boitempo, 2011.

OLSON, Mancur. A lógica da ação coletiva: os benefícios públicos e uma teoria dos grupos sociais. São Paulo: Edusp, 2015.

WEBER, Max. Economia e Sociedade: fundamentos da sociologia compreensiva. São Paulo/Brasília: Imprensa Oficial/Editora UnB, 1999. 